\title{
Effect of symptoms of climacteric syndrome, depression and insomnia on self-rated work ability in peri- and post-menopausal women in non-manual employment
}

\author{
Ewa Humeniuk ${ }^{1, A, C-F \oplus}{ }^{\oplus}$ Iwona Bojar ${ }^{2, A-C, E-F} \oplus$, Mariusz Gujski ${ }^{3, C-D \oplus}$, Dorota Raczkiewicz ${ }^{4, C-F} \oplus$ \\ ${ }^{1}$ Department of Pathology and Rehabilitation of Speech, Medical University, Lublin, Poland \\ ${ }^{2}$ Department of Women's Health, Institute of Rural Health, Lublin, Poland \\ ${ }^{3}$ Department of Prevention of Environmental Hazards and Allergology, Medical University, Warsaw, Poland \\ ${ }^{4}$ Institute of Statistics and Demography, Collegium of Economic Analysis, SGH School of Economics, Warsaw, Poland \\ A - Research concept and design, B - Collection and/or assembly of data, C - Data analysis and interpretation, \\ $D$ - Writing the article, E - Critical revision of the article, F- Final approval of article
}

Humeniuk E, Bojar I, Gujski M, Raczkiewicz D. Effect of symptoms of climacteric syndrome, depression and insomnia on self-rated work ability in peri- and post-menopausal women in non-manual employment. Ann Agric Environ Med. 2019; 26(4): 600-605. doi: 10.26444/aaem/112838

\begin{abstract}
I Abstract
Objective. The aim of the study was evaluation of the relationship between severity of symptoms of climacteric syndrome, depressive disorders and sleep problems, and the self-rated work ability of peri-menopausal and post-menopausal women in non-manual employment.

Materials and method. The study included 287 women aged 45-60 years, employed in various institutions as non-manual workers. Work Ability Index, Greene Climacteric Scale, Beck Depression Inventory, and Athens Insomnia Scale were used. Results. The examined peri-menopausal and post-menopausal women in non-manual employment obtained good work ability on the Work Ability Index. The severity of menopausal syndrome, according to the Greene Climacteric Scale, was moderate, placing the examined women between results for the general population of women and the pattern for menopausal women. Depressive disorders ranked between low mood and moderate depression. No depression was observed in 59\% of the women, whereas moderate depression was observed in 39\%, and severe depression in only $2 \%$. Sleep disorders were on the border of normal range. As many as $46 \%$ of the women had no sleep problems, which was on the border of normal range in $36 \%$. Only $19 \%$ of the examined women suffered from insomnia. Work ability correlated negatively with depression and insomnia severity, as well as with psychological and vasomotor symptoms of climacteric syndrome, but not to its somatic symptoms.

Conclusions. Preventing the occurrence and treatment of menopausal symptoms, sleep and mood disorders may contribute to maintaining the work ability of women in peri- and post-menopausal age.
\end{abstract}

\section{Key words}

depression, insomnia, peri- and post-menopausal women, work ability index, Greene Climacteric Scale, Beck Depression Inventory, Athens Insomnia Scale, climacteric syndrome

\section{INTRODUCTION}

According to current estimations, women constitute $42.0 \%$ of the working population in the European Union [1]. In recent decades, as a result of longer life span and demographic changes, women remain occupationally active for a longer time. In the United Kingdom, more than 3.5 million workers are women aged 50-65 [2], whereas in the United States, Canada and Sweden, more than one-third of women are aged over 45 [3]. It is estimated that in Western countries the number of older working women will continue to increase [1].

Menopause occurs between the ages 50-51, on average, and may last up to 10 years, which means that a considerable percentage of occupationally active women will be during the time of or after menopause [4]. This creates the need for better understanding of possible connections between

Address for correspondence: Iwona Bojar, Department of Women's Health, Institute of Rural Health in Lublin, Poland

E-mail: iwonabojar75@gmail.com

Received: 02.09.2019; accepted: 04.10.2019; first published: 07.11.2019 the problems experienced by women while going through menopause and their work ability.

The results of many studies indicate that menopause exerts a negative effect on work ability [3], and during this period of life, the highest annual decrease in work ability was observed [5]. A study of 896 women in the United Kingdom showed that such symptoms as poor concentration, fatigue, poor memory, depression and decreased confidence in own abilities had a negative effect on the work ability of women during the menopausal period [6]. However, the results of studies concerning the effect of menopause on work ability are unequivocal and show the presence of complex relationships.

Limitation of work ability and difficulties with performing occupational tasks may be due to changes taking place in the woman's body, which occur during peri- and post-menopausal period. These are caused by hormonal changes developing as a result of the cessation of the generative ovarian function. In accordance with the changes of the hormonal profile in women during this time, there may occur such symptoms as: hot flushes and sweats, insomnia, headaches, symptoms of dysuria, and emotional disorders [7]. 
Studies indicate that severe symptoms of the climacteric syndrome are significantly related with decreased work ability [8]. Similarly, sleep disorders and symptoms of low mood and depression may exert a negative effect on work ability. Many studies show that during the perimenopausal and post-menopausal period, women report the occurrence of sleep disorders [9]. These disorders include difficulty with falling asleep, waking up several times at night, and waking up earlier than desired [10]. Poor quality of sleep and an inadequate duration of sleep are related with negative health effects and the poor quality of life of women [11].

The objective of the study was evaluation of symptoms of climacteric syndrome, depressive disorders and sleep disorders, and their relationship with work ability in perimenopausal and post-menopausal women in non-manual employment.

\section{MATERIALS AND METHOD}

Study group. The study was conducted in 2016 at Institute of Rural Health in Lublin, Poland. The study included 287 women aged 45-60 years with non-manual employment in various institutions. A list of over 250 institutions in the Lublin region of eastern Poland was drawn up, in which women potentially interested in participating in the study performed non-manual, i.e. not physical work.

Subsequently, letters were sent by post to women in the institutions who met the inclusion criteria (age 45-60, non-manuto participate the health survey programme. Participation was voluntary and informed consent for participation was obtained from all volunteers.

At the first stage of the programme, socio-demographic and health interviews, as well as a medical examination, were conducted to verify compliance with the inclusion criteria and to exclude women who did not comply. At the second stage, blood samples were taken to determine the FSH and estradiol concentrations; ultrasonography of reproductive organs was also perfo5rmed. At the third stage, the women were asked to complete questionnaires according to the Greene Climacteric Scale, Beck Depression Inventory, Athens Insomnia Scale, Work Ability Index.

The group of women surveyed was homogeneous in terms of their type of work. All of them performed non-manual work, defined as: work requiring the participation of tracking and control activities, and also requiring the use of various types of technical devices, performed on the basis of fixed algorithms [12]. All the examined women performed nonmanual work of a similar nature: imitative, regular, 8-hour work day, 5 days a week, without night and not shift work, including night shift.

In menstruating women, FSH and estradiol concentrations were measured twice between days 3 and 5 of the cycl, in two consecutive cycles. In women who had not menstruated for at least 12 months, two measurements of FSH and estradiol concentrations were performed within one month. Next, the mean of two measurements was calculated and used to assess the reproductive stage of the women. As in the criteria of the Stages of Reproductive Aging Workshop (STRAW) [13, 14], the concentrations of FSH and estradiol, the ultrasound assessed number of antral follicles, and the regularity of menstrual cycles were included in the assessment of the reproductive stage. Due to financial limitations, $\mathrm{AMH}$ and inhibin B concentrations were not determined. Five reproductive periods were distinguished: late reproductive $(-3)$, early peri-menopause (-2), late peri-menopause (-1), early pos-tmenopause $(+1)$ and post-menopause $(+2)$. According to the aim of the study, women in the late reproductive period were not included. Due to the small number of women in the period of $+2(n=12)$, the +1 and +2 groups were combined into one group of post-menopausal women for further analysis. In this way, three groups of women at different periods of reproductive stage were obtained: early peri-menopause $(\mathrm{N}=98)$, late peri-menopause $(\mathrm{N}=43)$ and post-menopause $(\mathrm{N}=146)$.

The study was approved by the Ethics Committee of Institute of Rural Medicine in Lublin, Poland.

Greene Climacteric Scale. Cconsists of 20 items (answers to each question from $0-3$ ) and is used to examine the severity of symptoms of climacteric syndrome in three sub-scales:

a) psychological (total result maximum 33 scores);

b) somatic (21 scores);

c) vasomotor (6 scores) [15].

Beck Depression Inventory (BDI) by Aaron Beck [16]. Consists of 21 items. Respondents provide answers independently choosing statements which best describe their well-being. Level of depression is determined by summingup the number of scores obtained: lack of depression or low mood (0-10 scores), moderate depression (11-27 scores), and severe depression (28 scores or more).

Athens Insomnia Scale (AIS). An 8-item scale which allows quantitative measurement of the symptoms of insomnia according to the ICD-10 criteria [17]. The total result is within 0-24 scores. After calculating the results obtained from eight questions, respondents are qualified into three groups: normal range, most probably not suffering from insomnia ( $\leq 5$ scores); border of normal range, complying with the principles of sleep hygiene, and in the case of deterioration, consulting a doctor (6-10 scores); probably suffering from insomnia, requiring a doctor's consultation to supplement diagnostics and develop a strategy for therapy (>10 scores).

Work Ability Index (WAI). An instrument to assess selfrated work ability by the workers themselves [18], calculated based on answers to a series of questions which consider physical and psychological occupational requirements and state of health, as well as functional abilities of an employee. The result of the Index within 7-49 scores is classified as follows: 7-27 - low (restore work ability), 28-36 - moderate (improve work ability), 37-43 - good (support work ability), 44-49 - very good work ability (maintain work ability).

Statistical methods. Mean values (M) with standard deviations (SD) for continuous variables, and absolute (n) and relative numbers (\%) of occurrence of items for categorical variables, were estimated using STATISTICA 13 software. Test $F$ analysis of variance, $\chi^{2}$ test and Pearson's correlation coefficient were used. Regression analysis was not used because independent variables correlated with each other. Value of $\mathrm{p}<0.05$ was considered as a significant difference. 


\section{RESULTS}

Characteristics of the study group. The examined women were aged 45-60 and their age significantly differed among the three examined periods. The level of education of the examined women in early and late peri-menopausal period was similar, but the women in post-menopausal period were less educated than those at peri-menopausal age. The majority of the examined women were married (77\%), and their marital status did not significantly differ among the analyzed periods of reproductive life (Tab. 1).

Severity of symptoms of climacteric syndrome. The severity of psychological and vasomotor symptoms of climacteric syndrome, based on the Greene Climacteric Scale, was significantly lower in early peri-menopausal women than in late peri-menopausal and post-menopausal women. The severity of somatic symptoms did not significantly differ among the analyzed periods of reproductive life and, on average, was 5.0, which placed the examined women between the results for the general female population and the standards for menopausal women (Tab. 2).

Depressive and sleep disorders. The examined women obtained the mean result 9.8 \pm 7.4 scores in the Beck Depression Inventory (Tab, 3), which places them between low mood and moderate depression. No depression or low mood was observed in $59 \%$ of the examined women, while in $39 \%$ - moderate depression, and in $2 \%$ - severe depression were observed.

The examined women obtained the mean result $6.8 \pm 4.7$ scores in the Athens Insomnia Scale (Tab. 4). Nearly a half of the examined women (46\%) did not suffer from insomnia. Insomnia on the border of normal range was found in $36 \%$ of respondents, which indicted compliance with the principles of sleep hygiene, and in the case of deterioration - consultations with a doctor. 19\% of respondents suffered from insomnia and required a doctor's consultation in order to supplement diagnostics and develop a therapeutic strategy.
The numerical results (in scores) and score ranges of the Athens Insomnia Scale and Beck Depression Inventory did not significantly differ between the three examined periods of reproductive life.

Work Ability Index. The examined women obtained the work ability index from 26 - 49 scores; the mean 39.1 \pm 5.0 , meaning good work ability, on average (Tab. 5). The largest number of respondents (54\%) obtained good work ability, which should be supported. Fewer women (23\%) obtained moderate work ability, which should be improved. Even fewer respondents (20\%) obtained very good work ability, which should be maintained, while the least number of women (3\%) obtained low work ability, which should be restored. Both numerical results (in scores) and intervals of work ability index did not significantly differ between the three periods of reproductive life.

Correlations of work ability index with severity of depression, insomnia and symptoms of climacteric syndrome. Self-rated work ability of all the examined women negatively correlated with severity of depression, insomnia and psychological and vasomotor symptoms of climacteric syndrome, i.e. the respondents' work ability was better, the lower the severity of depression, insomnia and psychological and vasomotor symptoms of climacteric syndrome.. However, no correlation was found between the self-rated work ability and severity of somatic symptoms of climacteric syndrome (Tab. 6).

The early per-menopausal women' self-rated work ability did not correlate with severity of depression, insomnia and symptoms of climacteric syndrome. The late peri-menopausal women' self-rated work ability correlated negatively with the severity of insomnia, but not with the severity of depression or symptoms of climacteric syndrome. Self-rated work ability of the post-menopausal women correlated negatively with severity of depression, insomnia and psychological symptoms of climacteric syndrome.

Table 1. Characteristics of the study group

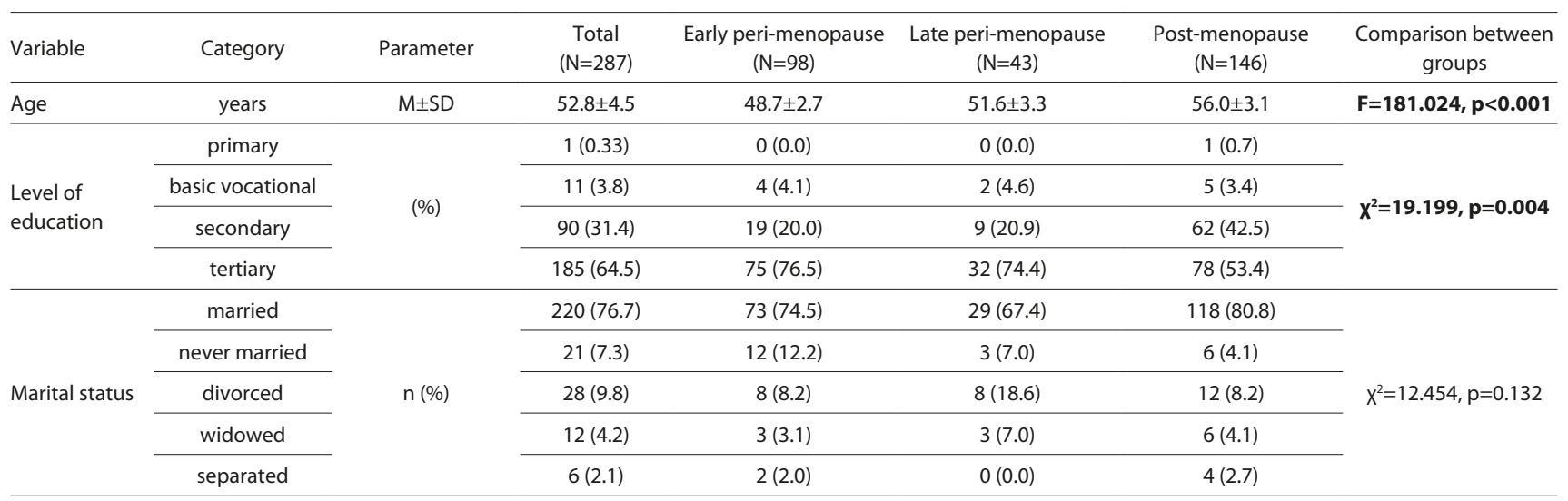

Table 2. Severity of climacteric symptoms in the women examined $(M \pm S D)$

\begin{tabular}{|c|c|c|c|c|c|}
\hline Greene Climacteric Scale symptoms: & Total & Early perimenopause & Late perimenopause & Postmenopause & Comparison between groups \\
\hline psychological & $9.6 \pm 6.6$ & $8.3 \pm 6.1$ & $9.7 \pm 7.3$ & $10.5 \pm 6.7$ & $F=3.199, p=0.042$ \\
\hline somatic & $5.0 \pm 3.8$ & $4.5 \pm 3.6$ & $5.0 \pm 3.9$ & $5.3 \pm 4.0$ & $F=1.273, p=0.282$ \\
\hline vasomotor & $1.7 \pm 1.9$ & $0.9 \pm 1.4$ & $2.0 \pm 1.8$ & $2.2 \pm 1.9$ & $F=16.296, p<0.001$ \\
\hline
\end{tabular}


Table 3. Severity of depressive disorders (BDI) in the women examined

\begin{tabular}{|c|c|c|c|c|c|c|}
\hline Depression & Parameter & Total & Early perimenopause & Late perimenopause & Postmenopause & Comparison between groups \\
\hline scores & $\mathrm{M} \pm \mathrm{SD}$ & $9.8 \pm 7.4$ & $8.9 \pm 8.3$ & $9.0 \pm 6.2$ & $10.5 \pm 7.1$ & $F=1.622, p=0.199$ \\
\hline lack of depression or low mood & \multirow{3}{*}{$\mathrm{n}(\%)$} & $170(59.2)$ & $66(67.4)$ & $25(58.1)$ & $79(54.1)$ & \multirow{3}{*}{$X^{2}=8.854, p=0.065$} \\
\hline moderate depression & & $111(38.7)$ & $28(28.6)$ & $18(41.9)$ & $65(44.5)$ & \\
\hline severe depression & & $6(2.1)$ & $4(4.0)$ & $0(0.0)$ & $2(1.4)$ & \\
\hline
\end{tabular}

Table 4. Severity of insomnia (AIS) in the women examined

\begin{tabular}{|c|c|c|c|c|c|c|}
\hline Insomnia & Parameter & Total & Early perimenopause & Late perimenopause & Postmenopause & Comparison between groups \\
\hline scores & $\mathrm{M} \pm \mathrm{SD}$ & $6.8 \pm 4.7$ & $6.2 \pm 4.5$ & $6.8 \pm 5.4$ & $7.2 \pm 4.6$ & $F=1.237, p=0.292$ \\
\hline normal range & \multirow{3}{*}{$\mathrm{n}(\%)$} & $131(45.6)$ & $50(51.0)$ & $22(51.2)$ & $59(40.4)$ & \multirow{3}{*}{$x^{2}=5.819, p=0.213$} \\
\hline border of normal range & & $102(35.5)$ & $35(36.0)$ & $11(25.6)$ & $56(38.4)$ & \\
\hline insomnia & & $54(18.8)$ & $13(13.3)$ & $10(23.3)$ & $31(21.2)$ & \\
\hline
\end{tabular}

Table 5. Work Ability Index (WAI) in the women examined

\begin{tabular}{|c|c|c|c|c|c|c|}
\hline WAI & Parameter & Total & Early perimenopause & Late perimenopause & Postmenopause & Comparison between groups \\
\hline scores & $\mathrm{M} \pm \mathrm{SD}$ & $39.1 \pm 5.0$ & $39.4 \pm 5.0$ & $38.9 \pm 5.0$ & $38.9 \pm 5.0$ & $F=0.305, p=0.737$ \\
\hline low (restore work ability) & \multirow{4}{*}{$\mathrm{n}(\%)$} & $8(2.8)$ & $2(2.0)$ & $1(2.3)$ & $5(3.4)$ & \multirow{4}{*}{$X^{2}=1.124, p=0.981$} \\
\hline moderate (improve work ability) & & $66(23.0)$ & $22(22.50)$ & $12(27.9)$ & $32(21.9)$ & \\
\hline good (support work ability) & & $156(54.4)$ & $54(55.1)$ & $22(51.1)$ & $80(54.8)$ & \\
\hline very good (maintain work ability) & & $57(19.9)$ & $20(20.4)$ & $8(18.6)$ & 29 (19.9) & \\
\hline
\end{tabular}

Table 6. Correlation coefficients of WAI with severity of depression, insomnia and symptoms of climacteric syndrome in the women examined

\begin{tabular}{|c|c|c|c|c|c|c|c|c|}
\hline \multirow{2}{*}{ Severity of } & \multicolumn{2}{|c|}{ Total } & \multicolumn{2}{|c|}{ Early perimenopause } & \multicolumn{2}{|c|}{ Late perimenopause } & \multicolumn{2}{|c|}{ Postmenopause } \\
\hline & r & $\mathrm{p}$ & r & $p$ & $r$ & $\mathrm{p}$ & $r$ & $\mathrm{p}$ \\
\hline depression & -0.186 & 0.002 & -0.052 & 0.611 & -0.270 & 0.080 & -0.266 & 0.001 \\
\hline insomnia & -0.237 & $<0.001$ & -0.072 & 0.480 & -0.296 & 0.050 & -0.318 & $<0.000$ \\
\hline psychological symptoms & -0.216 & $<0.001$ & -0.175 & 0.085 & -0.236 & 0.128 & -0.227 & 0.006 \\
\hline somatic symptoms & -0.078 & 0.190 & -0.167 & 0.100 & 0.111 & 0.478 & -0.070 & 0.404 \\
\hline
\end{tabular}

\section{DISCUSSION}

In this study, the women in peri- and post-menopausal period with non-manual employment obtained the mean Work Ability Index (WAI), indicating good work ability $(39.1 \pm 5.0$ scores), not significantly correlated to reproductive life stages. Almost $75 \%$ of the women obtained good or moderate work ability. The results of the study are similar to those obtained by other researchers. The WAI, on average, was $37.5 \pm 7.7$, and did not correlate with age or gender in a Polish study of a working sample population [19]. In Australia, very good or good work ability was observed in $81.5 \%$ of women aged 40-65, whereas moderate or low - in $18.5 \%$. In general, four per five examined women functioned well at work [20].

In general, women evaluated their productivity at work as high, and did not feel that the symptoms of menopause disturbed their work ability [21]. Therefore, it may be concluded that a considerable part of women maintain their work ability on a good level during the peri-menopausal and post-menopausal periods. Also, this period of life is not significantly associated with the degree of engagement in work and satisfaction with work [21].

The results of this study indicate that there exist factors which may significantly decrease the work ability on some women in the peri-menopausal and post-menopausal periods. These are: occurrence of symptoms of climacteric symptoms, depression and sleep disorders.

In the examined group of women, the severity of symptoms of climacteric syndrome was moderate - respectively, 9.6; 5.0; 1.7 (psychological, somatic, vasomotor), which places these women between the results for the general population of women and the standards for menopausal women. The severity of psychological and vasomotor symptoms of climacteric syndrome negatively correlated with the Work Ability Index. This means that in the examined women, the higher the work ability, the lower the severity of psychological and vasomotor symptoms of climacteric syndrome.

Studies conducted in France, Germany, Italy, Spain and the United Kingdom $(\mathrm{N}=3,801)$ showed that more than a half of respondents (50.3\%) experienced mild (24.6\%), moderate $(17.6 \%)$, or severe $(8.1 \%)$ vasomotor symptoms. Severe vasomotor symptoms negatively correlated with work ability [22]. Similar results were obtained in other studies where women with the symptoms of climacteric syndrome obtained significantly lower WAI values. Women who had high results according to the Greene Climacteric Scale were 8.4 times more exposed to low work ability, than the remaining women [3]. In Australian women, the intensity of 
vasomotor symptoms was significantly related to the degree to which their work was affected. This was especially true in the case of women with severe vasomotor symptoms, who reported by approximately $12 \%-27 \%$ more problems at work, compared to women who experienced only mild vasomotor symptoms [20]. It may therefore be concluded that severe and moderate vasomotor symptoms are strong predictors of low self-rated work ability.

It is an interesting observation that nearly $40 \%$ of women who were asked whether in their opinion the symptoms of climacteric syndrome exert a negative effect on their selfrated work ability, answered Yes, whereas 37\% disagreed or definitely disagreed, and the remaining $23 \%$ considered that these problems did not concern them [23]. This was confirmed by the results of other studies where the majority of women also did not believe that menopause symptoms negatively affected their work [24].

The risk of occurrence of depressed mood is twice to three times higher in peri-menopausal women than among those before menopause $[24,25]$. The prevalence of the symptoms of depression in women during menopause is 5.9\%-23.8\% [26,27].

In the current study, the examined women in peri- and postmenopausal periods with non-manual employment obtained the mean BDI indicating low mood or moderate depression. Severe depression was found only in $2 \%$ of women. The higher the work ability in the women, the lower the severity of depression. Similarly, in other studies of Polish women in the menopausal period, no respondents were identified with severe depression. The vast majority of respondents were placed within the ranges of lack of symptoms of depression or a mild form of depression. On average, the respondents obtained 10.64 scores in the BDI [28]. Thus, it may be presumed that depressive disorders are predictors of decreased work ability in peri-menopausal women.

In the current study, the majority of peri- and postmenopausal women with non-manual employment did not suffer from sleep disorders. These disorders were found in only $19 \%$ of the women examined, among whom the higher the self-rated work ability, the lower the severity of sleep disorders.

The results of studies by other researchers confirmed that sleep disorders are among the most frequently reported symptoms of menopause. More than a half of the women suffered from insomnia, poor quality of slee, or both [24]. In the United Kingdom, fatigue (59.0\%) and insomnia (50.0\%) were the most prevalent symptoms affecting work ability in peri- and post-menopausal women [29].

The frequency of sleep disorders increased with the women's age (from $39.7 \%$ in those aged $40-44$ to $45.2 \%$ in those aged 55-59 [30]. The greatest sleep disorders occurred in the women after menopause [31,32]. Nearly $2 / 3$ of the women perceived sleep disorders as significantly decreasing work ability [33]. Therefore, sleep disorders are one of the factors which may exert a negative effect on the work ability of peri- and post-menopausal women. Prevention and, if they occur, treatment of menopausal symptoms, sleep and mood disorders may contribute to maintaining the work ability of women at peri- and post-menopausal age.

In this study, selected methods were used to assess the symptoms of menopausal syndrome, depression, insomnia and work ability. Other tests and questionnaires could be also used in another study. It could also include a group of younger women, or at different stages of life, so that all variables and relationships between them in different age groups could be examined. The group for comparison could also be women working physically and men of similar age, which is a limitation of the current study.

\section{CONCLUSIONS}

1. Peri-menopausal and post-menopausal women in nonmanual employment obtained the Work Ability Index (WAI), indicating good self-rated work ability.

2. The severity of climacteric syndrome symptoms, based on the Greene Climacteric Scale, was moderate and placed the examined women between the results for the general population of women, and the standards for menopausal women.

3. The average severity of depressive disorders (BDI) was on the level between the results for low mood and moderate depression.

4. Average severity of sleep disorders (ASI) was on the border of normal range.

5. Work ability negatively correlated with the severity of psychological and vasomotor symptoms of climacteric syndrome, depressive disorders and sleep disorders.

\section{Acknowledgements}

This study was conducted in the Institute of Rural Health, Lublin, Poland, on the basis of the project "Mental and Physical Health of Women in the Perimenopausal and Postmenopausal Period in Terms of Preserving their Ability to Work" within the framework of the third stage of the multiannual program "Improving the Operational Safety and Working Conditions" financed in the years 2014-2016 in the field of research and development by the Ministry of Science and Higher Education/National Center for Research and Development. Program Coordinator: Central Institute for Labour Protection - National Research Institute

\section{REFERENCES}

1. Hammam RA, Abbas RA, Hunter MS. Menopause and work--the experience of middle-aged female teaching staff in an Egyptian governmental faculty of medicine. Maturitas 2012; 71: 294-300.

2. Office for National Statistics, Labour Market Statistics London: Office for National Statistics. http://www.ons.gov.uk/ons/rel/lms/labourmarket-statistics/may-2015/index.html.

3. Geukes M, van Aalstb MP, Robroekc SJW, Lavend JSE, Oosterhofa $\mathrm{H}$. The impact of menopause on work ability in women with severe menopausal symptoms. Maturitas 2016; 90: 1-8.

4. Hunter MS, Hardy C, Norton S, Griffiths A. Study protocol of a multicentre randomised controlled trial of self-help cognitive behaviour therapy for working women with menopausal symptoms. Maturitas 2016; 92: 186-92.

5. Ilmarinen JK, Tuomi K, Klockars M. Changes in the work ability of active employees over an 11-year period. Scand J Work Environ Health 1997; 23: 49-57.

6. Griffiths A, MacLennan SJ, Hassard J. Menopause and work: an electronic survey of employees' attitudes in the UK. Maturitas 2013; 76: 155-59.

7. Słopień R, Słopień A, Warenik-Szymankiewicz A, Sajdak S. Depressive symptoms and hormonal profile in climacteric women. Clin Exp Obstet Gynecol. 2015; 42: 285-91.

8. Silva RY, Câmara SM, Moreira MA et al. Correlation of Menopausal Symptoms and Quality of Life with Physical Performance in MiddleAged Women. Rev Bras Ginecol Obstet. 2016; 38: 266-72. 
9. Prather AA, Puterman E, Epel ES, Dhabhar FS. Poor sleep quality potentiates stress-induced cytokine reactivity in postmenopausal women with high visceral abdominal adiposity. Brain Behav Immun. $2014 ; 35: 155-62$.

10. Guidozzi F. Sleep and sleep disorders in menopausal women. Climacteric. 2013; 16: 214-19.

11. Ockene N, Shah KG, Hairston JG, Robinson M, Limacher L, Hale CB. Sleep duration, insomnia, and coronary heart disease among postmenopausal women in the Women's Health Initiative. J Womens Health (Larchmt) 2013; 22: 477-86.

12. Witczak W. Ability to hard mental work [Zdolność do ciężkiej pracy umysłowe]. Teka Kom. Praw. - OL PAN, 2008, 208-216. [in Polish].

13. Soules MR, Sherman S, Parrott E, et al. Executive summary: Stages of Reproductive Aging Workshop (STRAW). Climacteric 2001; 4: 267-72.

14. Harlow SD, Gass M, Hall JE, et al. STRAW + 10 Collaborative Group. Executive summary of the Stages of Reproductive Aging Workshop + 10: addressing the unfinished agenda of staging reproductive aging. J Clin Endocrinol Metab. 2012; 97(4): 1159-68.

15. Greene JG. A factor analytic study of climacteric symptoms. J Psychosom Res. 1976; 20: 425-30.

16. Kennedy P, Rogers BA. Anxiety and depression after spinal cord injury: A longitudinal analysis. Arch Phys Med Rehabil. 2000; 81: 932-37.

17. Fornal-Pawłowska M, Wołyńczyk-Gmaj D, Szelenberger D. Walidacja Ateńskiej Skali Bezsenności. Psychiatria Polska 2011; 45: 211-21.

18. Tuomi K, Ilmarinen J, Jahkola A, Katajarinne L, Tulkki A. Work Ability Index. Occupational Med. 2007; 57: 160.

19. Juszczyk G, Czerw A, Religioni U, Olejniczak D, Walusiak-Skorupa J, Banas T, Mikos M, Staniszewska A. Work Ability Index (WAI) values in a sample of the working population in Poland. Ann Agric Environ Med. 2019; 26(1): 78-84. https://doi.org/10.26444/aaem/91471

20. Gartoulla P, Bell RJ, Worsley R, Davis SR. Menopausal vasomotor symptoms are associated with poor self-assessed work ability. Maturitas 2016; 87: 33-39.

21. Hickey M, Riach K, Kachouie R, Jack G. No sweat: managing menopausal symptoms at work. J Psychosom Obstet Gynaecol. 2017; 38: 202-209.
22. Dibonaventura MD, Chandran A, Hsu MA, Bushmakin A. Burden of vasomotor symptoms in France, Germany, Italy, Spain, and the United Kingdom. Int J Womens Health 2013; 24: 261-69.

23. Jack G, Riach K, Bariola E, Pitts M, Schapper J, Sarrel P. Menopause in the workplace: What employers should be doing. Maturitas 2016; 85: 88-95.

24. Campbell KE, Dennerstein L, Finch S, Szoeke CE. Impact of menopausal status on negative mood and depressive symptoms in a longitudinal sample spanning 20 years. Menopause 2017; 24: 490-96.

25. Hickey M, Schoenaker DA, Joffe H, Mishra GD. Depressive symptoms across the menopause transition: findings from a large populationbased cohort study Menopause 2016; 23: 1287-93.

26. Bromberger JT, Schott LL, Avis NE et al. Psychosocial and health-related risk factors for depressive symptom trajectories among midlife women over 15 years: Study of Women's Health Across the Nation (SWAN). Psychol Med. 2018; 6: 1-10.

27. de Kruif M, Spijker AT, Molendijk ML. Depression during the perimenopause: A meta-analysis. J Affect Disord. 2016; 206: 174-80.

28. Barnaś E, Krupińska A, Kraśnianin E, Raś R. Psychosocial and occupational functioning women in menopause. Przegląd Menopauzalny 2012; 4: 296-304.

29. Griffiths A, Cox S, Griffiths R, Wong V. Women police officers: ageing, work and health. Report produced for the British Association for Women in Policing (BAWP). University of Nottingham, Institute of Work, Health and Organizations; 2006.

30. Blümel JE, Can A, Mezones-Holguín E, et al. A multinational study of sleep disorders during female mid-life. Maturitas 2012; 72: 359-66.

31. Hung HC, Lu FH, Ou HY, Wu JS, Yang YC, Chang CJ. Menopause is associated with self-reported poor sleep quality in women without vasomotor symptoms. Menopause 2014; 21: 834-39.

32. Kim MJ, Yim G, Park HY. Vasomotor and physical menopausal symptoms are associated with sleep quality. PLoS One 2018; 20: e0192934.

33. Sun D, Shao H, Li C, Tao M. Sleep disturbance and correlates in menopausal women in Shanghai. J Psychosom Res. 2014; 76: 237-41.

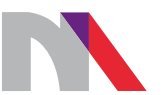

Ministry of Science and Higher Education

Republic of Poland

Generation of the DOI (Digital Object Identifier) - task financed under the agreement No. 618/P-DUN/2019 by the Minister of Science and Higher Education 